\title{
The effect of Facebook users' satisfaction and trust on stickiness: The role of perceived values
}

\author{
Mahmoud Maqableh $^{a^{*}}$, Mohammad Abuhashesh ${ }^{\mathrm{b}}$, Laila Dahabiyeh ${ }^{\mathrm{a}}$, Mohammad K. Al Nawayseh ${ }^{\mathrm{a}}$ and \\ Ra'ed Masa'deh ${ }^{a}$
}

${ }^{a}$ Department of Management Information Systems, School of Business, The University of Jordan, Amman, Jordan ${ }^{b}$ E-Marketing and Social Media Department, Princess Sumaya University for Technology (PSUT), Amman, Jordan

\section{CH R O N I C L E ABS T RAC T}

Article history:

Received: March 13, 2021

Received in revised format: April

10, 2021

Accepted: June 14, 2021

Available online: June 14, 2021

Keywords:

Facebook

Stickiness

Satisfaction

Trust

Perceived values

Social media

\begin{abstract}
This study aims to explore the impact of satisfaction and trust on stickiness to Facebook. Also, it proposed that hedonic value, emotional value, and social value act as critical antecedents to Facebook stickiness. A quantitative methodology is used to examine the research questions. The research model was tested with data from 511 university students and five academic professors using an online survey. The proposed hypotheses were tested using regression analysis. Furthermore, Data were collected from targeted participants with Facebook experience, among the 511 participants, 353 were females (69.1\%), and 158 were males (30.9\%). The SEM analysis showed that satisfaction positively and significantly did affect stickiness, where trust did not. Also, results showed while hedonic value affected satisfaction, it did not impact trust. Hence, the results confirmed that hedonic value served as important value concerns for Facebook users. Nevertheless, the study found that both emotional value and social value impacted satisfaction and trust. The current research has enriched the existing study in the fields of customers' satisfaction and trust on stickiness to Facebook. Moreover, this research is one of the earliest studies that proved that customer value creation serves as an important driving factor for customer satisfaction to generate stickiness to SNS. This study's results help policymakers and designers of SNS to understand what value factors affect users' stickiness to Facebook. Their marketing plans and decisions can be accordingly adjusted. This study suggests that marketers need to pay full attention to social value by adding more interactive features such as comments, likes, and shares in order to build social image and increase one's social influence.
\end{abstract}

\section{Introduction}

The rise of social networking sites is fueled by web 2.0 technologies, allowing users to be both consumers and creators of the online content. Facebook is considered as the world's largest social networking site with more than 2 billion daily users worldwide. Facebook allows users to create content such as text and video, share information and make connections. Despite its positive aspects, Facebook has several negative implications such as information and social overload, it may also trigger negative emotions which may lead to decrease in life satisfaction. Recent statistics find that the usage of SNS in general has declined and users start switching from one platform to another (Lin et al., 2014). Thus, SNSs should work hard to attract users to stay longer and to increase the switching cost by enhancing usefulness and usability of their services (Shao et al., 2020). Moreover, since the Cambridge Analytica scandal, Facebook has been facing continuous criticism for its improper privacy policies from its users, legislators and the society as a whole. This matter has garnered considerable attention because the content on Facebook is co-constructed by the user and others (Jia \& Xu, 2015). Accordingly, any privacy risk on an individual will spill over to other users in his/her circle. Ramifications from this scandal were felt as there was a $66 \%$ drop in

* Corresponding author.

E-mail address: maqableh@ju.edu.jo (M. Maqableh)

(C) 2021 by the authors; licensee Growing Science, Canada. doi: $10.5267 /$ j.ijdns.2021.6.009 
users' trust in Facebook (Weisbaum, 2019), and a 20\% decrease in the number of actions on Facebook (e.g. like, posts, share) (Alex, 2019). Facebook users realized that the giant social media platform business model relies mainly on collecting and selling their information. Recently, Facebook's new child WhatsApp announced that it will change its privacy policy, allowing Facebook to collect customer personal data. As a result, millions of users left WhatsApp and started looking for more secure platforms like telegram and signal (Duffy, n.d.).

Following this scandal, Facebook has started revising its privacy policies and taking stringent rules to regain users' trust. However, does trust really influence users' intention to keep using Facebook? If not, what Facebook should consider to make users more satisfied with its services. Moreover, in the face of continuous privacy concerns, what are the other motivational factors that affect users' stickiness to Facebook? Answering these questions and understanding the factors contributing to Facebook stickiness is critical for the long-term sustainability of social networking sites (SNS). Stickiness refers to the website's ability to attract and retain users, this includes users' frequency and duration of visits (Authors, 2016; Shao et al., 2020). Stickiness to Facebook has little attention in academic literature compared to other related concepts, it goes beyond usage intention or continuous intention of Facebook (Hsu \& Lin, 2020; Shao et al., 2020). For SNSs, stickiness covers all the aspects of users' loyalty, commitment, engagement and usability for that SNS (Gong et al., 2018). Website stickiness depends on users perceived values, online trust, satisfaction and website quality (Gong et al., 2018; Thomas, 2020; Hsu \& Lin, 2016). Accordingly, this research aims to investigate the factors that influence users' stickiness to Facebook through the impact of satisfaction and trust. Building on the IS success model (DeLone \& McLean, 2003) and the value-based model (Yang \& Lin, 2014), this research proposes an integrated model to explain the factors that affect users' stickiness to Facebook. This paper is organized as follows. Next, we draw on relevant literature to develop our research model and hypotheses. We then describe the research method and provide the results of the empirical tests. Finally, we discuss our findings and offer valuable theoretical and practical implications.

\section{Theoretical Framework and Hypotheses Development}

Previous literature on stickiness has mainly adopted the value-based model to explain users' continuous use of SNS. This stream of research focuses on the multidimensional nature of values and examines how different types of values (e.g. information, social, hedonic, emotional) directly influence users' stickiness to SNS (Hong et al., 2017; Yang et al., 2018; Ibrahim \& Borhan, 2020; Cocosila \& Igonor, 2014). However, another stream of research provides evidence of the role of relationship quality constructs from the IS success model (trust and satisfaction) on stickiness (Wu et al., 2014; Amoroso \& Chen, 2017; Tsai \& Hung, 2019; Ye et al., 2019; Lee et al., 2017). In this paper, we integrate these two views and argue that stickiness is a matter of users' trust in and satisfaction towards Facebook and that social, hedonic and emotional values affect the levels of trust and satisfaction.

\subsection{Satisfaction}

The literature on SNS stickiness and continuous use emphasizes the important role of satisfaction and trust on retaining customers (Wu et al., 2014; Ye et al., 2019). Satisfaction is the comparison result between expected performance and actual performance (Odel, 2001). Before using SNS, users form an expectation of the level of services in SNS. This expectation acts as a baseline for evaluating the platform. If upon using the SNS users' expectation was confirmed, users are perceived to be satisfied with the SNS. Businesses struggle to improve their products and services in order to better satisfy their customers' demands (Wu et al., 2014). Researchers found that if users have positive experience with SNS they are more likely to stick to these sites and keep using their services. Moreover, Bhattacherjee (2001) showed that dissatisfaction (i.e. not meeting expectations) causes users to discontinue IS use even if they perceive the system to be useful. In social networks context it has been confirmed that satisfaction positively affects continuous intention and stickiness. Accordingly, satisfaction is critical for the stickiness of SNS. We suggest that satisfaction has a positive impact on stickiness to SNS.

\section{H1. Satisfaction has a positive impact on stickiness to SNS.}

\subsection{Trust}

The lack of physical presence in SNS along with the absence of formal governance rules and the spread of privacy scandals make trust in SNS indispensable. We define trust as the belief that SNS will perform actions that are beneficial to its users or at least do not cause them any harm. Trust role lies in minimizing opportunistic behavior (Tsai \& Hung, 2019) and forming an expectation that SNS will deliver its services as promised (Wu et al., 2014). Trust is a complex concept that comprises several constructs (Lita \& Meuthia, 2018; Herzallah \& Mukhtar, 2016). Lankton and McKnight (2011) divide trust in SNS into trust beliefs related to interpersonal characteristics such as integrity, benevolence, and caring about others welfare and refraining from being selfish, and trust beliefs related to technology characteristics such as functionality and helpfulness (Lankton \& McKnight, 2011). While the former type relates more to the affection dimension of trust (Tsai \& Hung, 2019), the latter perceive trust to be formed through rational calculations of costs and benefits (Kim et al., 2008); once the benefits of engaging in a SNS outweigh the benefits, then users confer trust to that site. The relationship between trust and continuous 
use of SNS has been examined in the literature. When customers trust a website, they are more likely to keep using its services. In a similar vein, researchers found that uncertainty and lack of trust are one of the key factors for quitting SNS (Chang et al., 2017; Xing Zhang et al., 2018). Trust influences stickiness to SNS (Sun et al., 2014), users usually return to websites that they trust will satisfy their needs (Ye et al., 2019). We thus argue that trust has a positive impact on stickiness.

H2. Trust has a positive impact on stickiness to SNS.

Trust's multidimensional nature indicates that it comprises a variety of values. The values one can derive from SNS are important sources of trust (Grabner-Kräuter \& Bitter, 2014). Value is known as "the trade-off between total benefits received and total sacrifices" (Kim et al., 2008). When determining the value of SNS users assess the values received from using the platform by comparing what they have to offer and what they receive in return (Amoroso \& Chen, 2017). Extant literature has approached value differently. For instance, the literature on economics has emphasized the economic (monetary) and information values, while the field of social psychology focused more on social and emotional values. Acknowledging the complexity and the multi-dimensionality of values is critical since users consider a variety of factors when making decisions (Kim et al., 2008). In subsequent sections, we focus on the impact of hedonic, social, and emotional values and explain their relationship with trust and satisfaction.

\subsection{Perceived Values}

Perceived value in business research has been defined as the overall cost and benefit assessment of a product or service (Bagozzi \& Yi, 1988). The dimensions of perceived value were categorized as extrinsic (utilitarian, hedonic) and intrinsic (economic, social) values (Holbrook et al., 2006). According to the value-based model and motivation theory (Hsu \& Lin, 2020; Lin et al., 2011), this research classifies perceived values in the social networks' context as utilitarian, social and emotional values.

\subsubsection{Hedonic value}

A primary reason why users remain active in SNS is the high level of enjoyment they receive from these sites (Ha \& Pan, 2018). Hedonic value is related to pleasurable experiences and a sense of happiness and fulfillment following the engagement in SNS, regardless of the functionalities and utilities offered. Hedonic value has been found to be a critical value users look for in SNS (Cocosila \& Igonor, 2015) and can be more important than the social value (Sun et al., 2014). Hedonic value can be manifested in enjoyable content such as games, where users join Facebook and remain attracted to it because of the opportunity to participate in multiplayer online games supported by the platform (Yang \& Lin, 2014). Hedonic value is not limited to games but also extends them to involve embedding playful and fun features in social commerce. Wongkitrungrueng and Assarut (2018) examined Facebook Live and its effect on hedonic value (Wongkitrungrueng \& Assarut, 2020). They found that sellers' use of live streaming for products improved customers' shopping experience by making it more enjoyable and that hedonic value has a positive effect on customers' trust. Other researchers have found that the more enjoyable experiences SNS offer, the higher the user satisfaction (Gan \& Wang, 2017) (C. L. Hsu \& Lin, 2015) (Sweeney \& Soutar, 2001).

Therefore, we argue that hedonic value has a positive impact on trust and satisfaction.

\section{H3. Hedonic value has a positive impact on trust.}

\section{H4. Hedonic value has a positive impact on satisfaction.}

\subsubsection{Social value}

SNS are primarily seen as platforms for social communication where users participate to gain a variety of social benefits such as improving one's self-esteem and social status (Cocosila \& Igonor, 2015; Yoo et al., 2014; Noordin et al., 2018). Interactive features such as comments, like, and share help in building social image and increasing one's social influence (Yang et al., 2018). The critical mass of SNS, especially Facebook, make them attractive for users looking for social engagement and bonding opportunities with society. This drives users to associate SNS with some of the trust attributes such as cooperativeness (Grabner-Kräuter \& Bitter, 2014). Another relevant and critical attribute of trust in SNS is group identification (GrabnerKräuter \& Bitter, 2014). By communicating with other users who share similar beliefs, knowledge, interests and values, users identify themselves with SNS where the latter help them become part of a larger collective identity (Grabner-Kräuter \& Bitter, 2014; Tsai \& Hung, 2019). Such social interactions not only enhance customers' trust (Ye et al., 2019) but also contribute to developing satisfaction towards SNS (Yu et al., 2013; Gan \& Wang, 2017). Therefore, we argue that social value has a positive impact on trust and satisfaction. 
H5. Social value has a positive impact on trust.

H6. Social value has a positive impact on satisfaction.

\subsubsection{Emotional value}

Emotional value is a form of intrinsic benefit users receive from SNS. People join SNS to gain emotional support from friends and people in their social circle regardless of the effectiveness or the efficiency of the outcomes (Lee et al., 2014). This support creates a safe environment for sharing a personal feeling with others (Sun et al., 2014). Emotional attachments conferred in SNS influence trust judgements. A study by Tsai and Hung (2018) revealed that the absence of psychological support and reassurances diminished users' trust in SNS (Tsai \& Hung, 2019). Users perceive SNS as sources of empathy and caring feelings, and they experience satisfaction when such emotional needs are fulfilled through SNS. Accordingly, we suggest that emotional value has a positive impact on trust and satisfaction.

H7. Emotional value has a positive impact on trust.

H8. Emotional value has a positive impact on satisfaction.

\section{Research Methodology}

This section presents the research methodology. It consists of the research model of the study's independent, mediating, and dependent variables, research hypotheses, as well as data collection tool and research population and sample.

\subsection{Research Model}

Fig. 1 shows the study model that demonstrates the independent variable, the mediating variables, the dependent variables, and the proposed association between them.

\subsection{Measurement development}

Table 1 shows that six variables (hedonic value, emotional value, social value, and trust, satisfaction, and stickiness) were measured in this research. These variables were adopted from previously validated studies where standard measures were used (Yang \& Lin, 2014; Xin Zhang et al., 2020; Zhang et al., 2017; Wang et al., 2020). A 5-point Likert scale ranging from " 1 = strongly disagree" to " $5=$ strongly agree" is used to measure the questionnaire items for the six variables. The preliminary instrument was pre-tested in eight semi-structured interviews with Facebook users and five academic professors from the Department of Management Information Systems (MIS) at the University of Jordan to test its completeness, relevance, clarity, and length. This process led to numerous minor amendments to the survey questions.

\section{Table 1}

Constructs and measurement items

\begin{tabular}{|c|c|}
\hline Construct & Measurement Items \\
\hline Hedonic Value (HV) & $\begin{array}{l}\text { HV1: Compared to other things I could have done, the time spent online at the Facebook site was truly enjoyable. } \\
\text { HV2: I enjoyed being immersed in exciting new information on Facebook sites. } \\
\text { HV3: During the navigating Facebook processes, I felt the excitement of the hunt. }\end{array}$ \\
\hline Emotional Value (EV) & $\begin{array}{l}\text { EV1: I receive adequate emotional concern from people using Facebook. } \\
\text { EV2: I feel relieved by getting sympathy from online people using Facebook. } \\
\text { EV3: I have been encouraged by friends on Facebook. }\end{array}$ \\
\hline Social Value (SV) & $\begin{array}{l}\text { SV1: Facebook use helps me feel accepted. } \\
\text { SV2: Facebook use improves the way I am perceived. } \\
\text { SV3: The fact I use Facebook makes a good impression on other people. } \\
\text { SV4: Facebook use gives me social approval. }\end{array}$ \\
\hline Trust (TR) & $\begin{array}{l}\text { TR1: People on Facebook are trustworthy. } \\
\text { TR2: I trust Facebook information to be true. } \\
\text { TR3: I usually trust Facebook unless it gives me a reason not to trust it. } \\
\text { TR4: Overall, Facebook is trustworthy. }\end{array}$ \\
\hline Satisfaction (SA) & $\begin{array}{l}\text { SA1: I was very content with Facebook. } \\
\text { SA2: I was very pleased with Facebook. } \\
\text { SA3: I felt delighted with Facebook. } \\
\text { SA4: Overall, I was satisfied with Facebook. }\end{array}$ \\
\hline Stickiness (ST) & $\begin{array}{l}\text { ST1: If could, I would visit the Facebook website often as I can. } \\
\text { ST2: I will recommend my friends and family members to use Facebook. } \\
\text { ST3: I intend to link to Facebook every time I am online in the future. } \\
\text { ST4: I intend to stay a longer time on Facebook rather than any alternative. }\end{array}$ \\
\hline
\end{tabular}




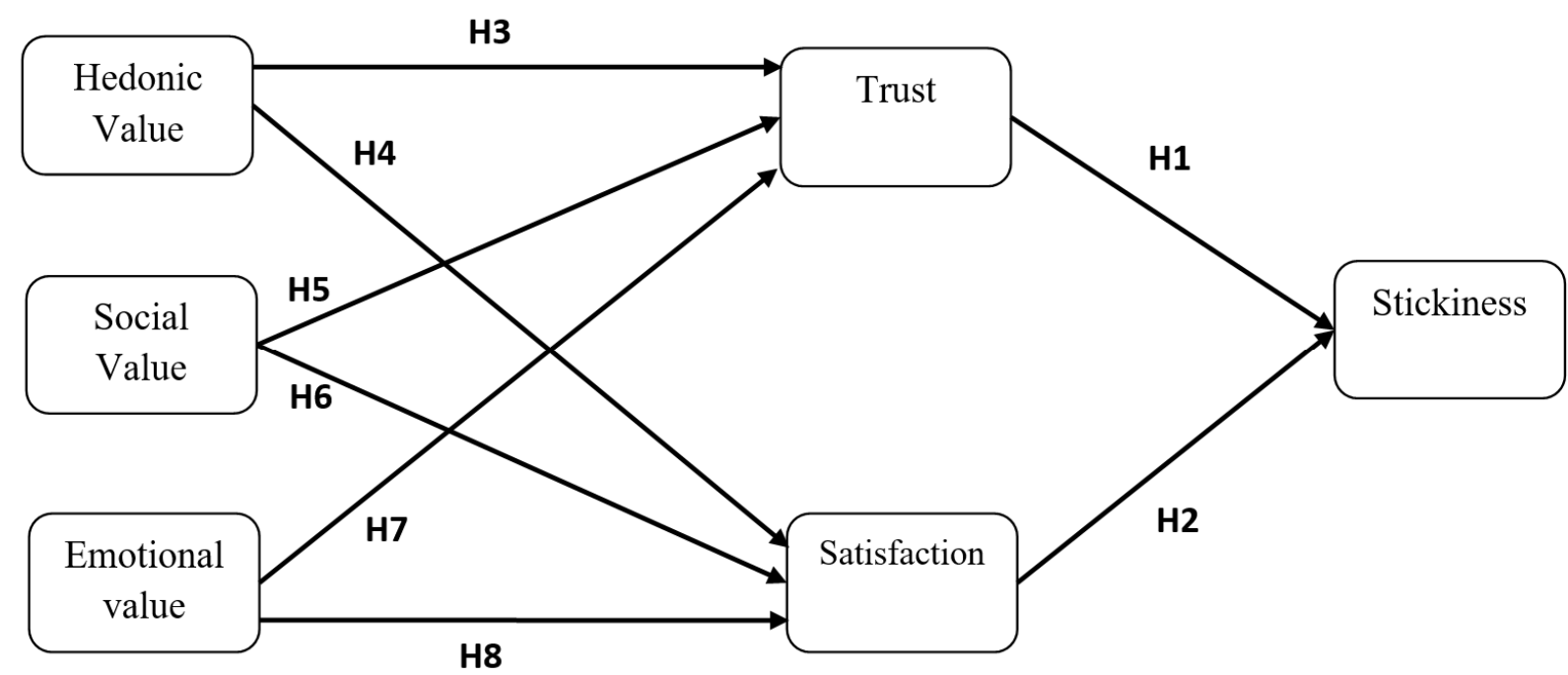

Fig. 1. Research model

\subsection{Sample and data collection}

Data were collected from targeted participants with Facebook experience using an online survey. According to the University of Jordan registration unit, the study population consisted of 4,000 bachelor students from the School of Business. Participants were selected opportunely from the school. However, what constitutes an adequate sample size for regression analysis is uncertain among researchers. Some researchers (O'Rourke \& Hatcher, 2013) recommend that the sample size of a study that applies multiple linear regression should be 100 participants or more than five times the number of items measured. The questionnaire was made up of 22 items, so the sample size should be over 160 students. Also, Hair et al. (2014) recommended between 100 and 200 while (Krejcie \& Morgan, 1970) required 351 from a population of 4,000. Therefore, the number of returned surveys is 511 that meet the requirement of sample size for a structural equation model and show adequate representation with the highest probability assessment. In Table 2, the respondents' characteristics of this study are summarized. As shown in Table 2, among the 511 participants, 353 were females $(69.1 \%)$, and 158 were males (30.9\%). Many of participants were between $20-22$ years old $(379,74.2 \%)$, followed by the $17-19$ years old $(92,18 \%)$, and then 23 years old and above $(40,7.8 \%)$.

Table 2

Description of the respondents' demographic profiles

\begin{tabular}{|c|c|c|c|}
\hline Category & Category & Frequency & Percentage $\%$ \\
\hline \multirow[t]{3}{*}{ Gender } & Male & 158 & 30.9 \\
\hline & Female & 353 & 69.1 \\
\hline & Total & 511 & 100 \\
\hline \multirow[t]{4}{*}{ Age (Years) } & $17-19$ & 92 & 18.0 \\
\hline & $20-22$ & 379 & 74.2 \\
\hline & 23 and above & 40 & 7.8 \\
\hline & Total & 511 & 100 \\
\hline \multirow[t]{6}{*}{ Academic level } & Year 1 & 18 & 3.5 \\
\hline & Year 2 & 151 & 29.5 \\
\hline & Year 3 & 165 & 32.3 \\
\hline & Year 4 & 146 & 28.6 \\
\hline & Year 5 and above & 31 & 6.1 \\
\hline & Total & 511 & 100 \\
\hline \multirow{5}{*}{$\begin{array}{l}\text { Students spend on Social Net- } \\
\text { working activities daily (Hour) }\end{array}$} & Less than 1 & 47 & 9.2 \\
\hline & $1-3$ & 221 & 43.2 \\
\hline & $4-6$ & 173 & 33.9 \\
\hline & More than 6 & 70 & 13.7 \\
\hline & Total & 511 & 100 \\
\hline \multirow[t]{5}{*}{ Using Facebook Sites (Weekly) } & Less than 10 & 50 & 9.8 \\
\hline & $10-29$ & 176 & 34.4 \\
\hline & $30-50$ & 140 & 27.4 \\
\hline & More than 50 & 145 & 28.4 \\
\hline & Total & 511 & 100 \\
\hline
\end{tabular}


Furthermore, most respondents were at the second, third and fourth years of education (462, 90.4\%), and the First and fifth year and above students (49, 9.6\%). Regarding the number of hours spent on social networking every day, most participants used Facebook between 1-3 hours daily $(221,43.2 \%)$, and 4-6 hours per day $(173,33.9 \%)$, and more than 6 hours $(70$, 13.7\%). As for the number of Times using Facebook weekly, participants used Facebook for 10-29 times (176, 34.4\%), and more than 50 times $(145,28.4 \%)$, followed $30-50$ times by $(140,27.4 \%)$, and less than ten times $(50,9.8 \%)$ respectively. Table 2 indicates that $69.1 \%$ of the respondents were females, and most of them ranged from 20 to 22 years $(74.2 \%)$, and in Year 3. In addition, 43.2\% spend 1-3 hours daily on Social Networking activities. Also, most of them used Facebook sites 1029 weekly.

\section{Data Analysis and Results}

To examine the relations among the research variables, reliability and validity analyses were performed, descriptive analysis and SEM analysis was used to examine the research hypotheses.

\subsection{Descriptive analysis}

To describe the responses and therefore, the attitude of the respondents toward each question they were raised in the survey, the mean and the standard deviation were estimated (Pallant, 2005). The level of each item was determined by the following formula (Sekaran and Bougie, 2013): (highest point in Likert scale - lowest point in Likert scale) / the number of the levels used $=(5-1) / 5=0.80$, where 1-1.80 reflected by "very low", 1.81-2.60 reflected by "low", 2.61-3.40 reflected by "moderate", 3.41-4.20 reflected by "high", and 4.21-5 reflected by "very high". Then the items were being ordered based on their means. Tables 3 demonstrates the results.

Table 3

Overall mean and standard deviation of the study's variables

\begin{tabular}{|c|c|c|c|c|c|}
\hline $\begin{array}{l}\text { Type of Variable } \\
\text { Independent Variables }\end{array}$ & Variables & Mean & Standard Deviation & Level & Order \\
\hline & Hedonic Value & 3.4866 & 0.75910 & High & 1 \\
\hline & Emotional Value & 2.9159 & 0.78221 & Moderate & 3 \\
\hline & Social Value & 3.1703 & 0.73373 & Moderate & 2 \\
\hline \multicolumn{6}{|l|}{ Mediating Variables } \\
\hline & Trust & 2.3249 & 0.74731 & Low & 2 \\
\hline & Satisfaction & 3.3552 & 0.71594 & Moderate & 1 \\
\hline Dependent Variable & Stickiness & 3.3992 & 0.75885 & Moderate & - \\
\hline
\end{tabular}

\subsection{Measurement model}

AMOS software version 22 was used to examine the research hypotheses. The analysis was performed by employing a Confirmatory Factor Analysis (CFA) to study if the data fits the hypothesized measurement model. Then Structural Equation Modelling (SEM) is used for examining the structural model, by which the latter is tested by path analysis using latent variables (Bagozzi \& Yi, 1988; Hair, 2007; Kline, 2011). To achieve the model fit, a robust statistics test such as $\mathrm{x}^{2} /$ degrees of freedom (df), the Incremental Fit Index (IFI), Tucker-Lewis Index (TLI), Comparative Fit Index (CFI), Goodness-of-Fit Index (GFI), Adjusted Goodness-of-Fit Index (AGFI), and the Root Mean Square Error of Approximation (RMSEA) were selected (see Table 5). However, while the preliminary CFA model did not demonstrate an adequate fit, two items (EV2 and SV2) were removed to acquire an improved fit for the measurement model as the chi-square $\left(\mathrm{x}^{2} / \mathrm{df}\right)$ value of the model was 2.733 ; threshold must be between 2 and 5), IFI $=0.91$, TLI $=0.91, \mathrm{CFI}=0.92, \mathrm{GFI}=0.91, \mathrm{AGFI}=0.93$, and RMSEA $=0.076$. Consequently, the measurement form indicated an acceptable fit to the data (Hair, 2007)(Rex B. Kline, 2011)(Newkirk \& Lederer, 2006).

Table 4

Measurement model fit indices

\begin{tabular}{llllllll}
\hline Model & $\mathbf{x}^{2} / \mathbf{d f}$ & IFI & TLI & CFI & GFI & AGFI & RMSEA \\
\hline $\begin{array}{l}\text { Initial } \\
\text { Model }\end{array}$ & 3.104 & 0.86 & 0.87 & 0.88 & 0.87 & 0.89 & 0.081 \\
$\begin{array}{l}\text { Final Model } \\
\begin{array}{l}\text { Threshold } \\
\text { Values }\end{array}\end{array}$ & 2.733 & 0.91 & 0.91 & 0.92 & 0.91 & 0.93 & 0.076 \\
\hline
\end{tabular}

In addition, the current research examined the internal consistency of multi-item constructs by evaluating Cronbach's alpha which should be more than 0.6, as recommended by (Hair et al., 2014); and to the research items having a factor loading above 0.6 , as suggested by scholars (Creswell, 2009). The composite reliabilities for all constructs should surpass the threshold 
of 0.6 (Bagozzi \& Yi, 1988); and The Average Variance Extracted (AVE) from a set of measurements of a latent variable ought to be over 0.5, as recommended by Bagozzi and Yi (1988) and Creswell (2009). The findings of Cronbach's alpha, factor loadings, composite reliability, and AVE for the research variables are presented in Table 5. Cronbach's alpha for the entire constructs surpassed 0.7, and the entire indicators of the factor loadings were above 0.50 , as a consequence representing confirmation of convergent validity (see (Bagozzi \& Yi, 1988; Creswell, 2009; Larcker et al., 1981). Also, convergent validity was proved since every value of AVE surpassed 0.50 (Bagozzi \& Yi, 1988; Hair et al., 2014). The means, standard deviations, AVEs, and the square of correlations along with constructs are revealed in Table 5. Indeed, all of the associations involving pairs of constructs were less than the square root of the AVE estimates of the two constructs, verifying discriminant validity (see (Hair et al., 2014)).

Table 5

Properties of the final measurement model

\begin{tabular}{|c|c|c|c|c|c|c|c|}
\hline $\begin{array}{l}\text { Constructs and } \\
\text { Indicators }\end{array}$ & $\begin{array}{l}\text { Factor } \\
\text { Loadings }\end{array}$ & $\begin{array}{l}\text { Std. } \\
\text { Error }\end{array}$ & $\begin{array}{l}\text { Square } \\
\text { Multiple } \\
\text { Correlation }\end{array}$ & $\begin{array}{l}\text { Error } \\
\text { Variance }\end{array}$ & $\begin{array}{l}\text { Cronbach } \\
\text { Alpha }\end{array}$ & $\begin{array}{l}\text { Composite } \\
\text { Reliability* }\end{array}$ & AVE** \\
\hline Hedonic Value & & & & & 0.612 & 0.77 & 0.53 \\
\hline HV2 & 0.723 & 0.195 & 0.523 & 0.338 & & & \\
\hline HV3 & 0.607 & 0.178 & 0.368 & 0.386 & & & \\
\hline Emotional Value & & & & & 0.669 & 0.67 & 0.51 \\
\hline EV2 & 0.749 & 0.121 & 0.561 & 0.505 & & & \\
\hline Social Value & & & & & 0.639 & 0.74 & 0.53 \\
\hline SV1 & 0.631 & $* * *$ & 0.398 & 0.400 & & & \\
\hline SV3 & 0.500 & 0.085 & 0.240 & 0.359 & & & \\
\hline SV4 & 0.751 & 0.101 & 0.564 & 0.331 & & & \\
\hline Trust & & & & & 0.750 & 0.81 & 0.52 \\
\hline TR1 & 0.599 & $* * *$ & 0.359 & 0.414 & & & \\
\hline TR3 & 0.675 & 0.111 & 0.455 & 0.373 & & & \\
\hline TR4 & 0.633 & 0.101 & 0.401 & 0.451 & & & \\
\hline Satisfaction & & & & & 0.806 & 0.84 & 0.58 \\
\hline SA1 & 0.589 & $* * *$ & 0.347 & 0.572 & & & \\
\hline SA2 & 0.782 & 0.097 & 0.612 & 0.296 & & & \\
\hline SA3 & 0.790 & 0.099 & 0.624 & 0.292 & & & \\
\hline SA4 & 0.723 & 0.098 & 0.523 & 0.393 & & & \\
\hline Stickiness & & & & & 0.789 & 0.81 & 0.51 \\
\hline ST1 & 0.809 & $* * *$ & 0.655 & 0.314 & & & \\
\hline ST2 & 0.695 & 0.060 & 0.483 & 0.538 & & & \\
\hline ST3 & 0.750 & 0.056 & 0.563 & 0.386 & & & \\
\hline ST4 & 0.545 & 0.058 & 0.297 & 0.650 & & & \\
\hline \multicolumn{8}{|c|}{$\begin{array}{l}\text { * Employing (Larcker et al., 1981) formula, the composite reliability calculation is e } \\
\text { Composite Reliability }=(\Sigma \mathrm{Li})^{2} /\left((\Sigma \mathrm{Li})^{2}+\Sigma \mathrm{Var}(\mathrm{E} i)\right) \\
\text { where } \mathrm{Li} \text { is the standardised factor loadings for each indicator, and Var (Ei) is the } \\
\text { error variance associated with the individual indicator variables. } \\
* * \text { The formula for the variance extracted is: } \\
\text { Average Variance Extracted }=\Sigma \mathrm{L} i^{2} /\left(\Sigma \mathrm{Li}^{2}+\Sigma \mathrm{Var}(\mathrm{E} i)\right) \\
\text { where Li is the standardised factor loadings for each indicator, and Var (Ei) is the } \\
\text { error variance associated with the individual indicator variables. }\end{array}$} \\
\hline
\end{tabular}

error variance associated with the individual indicator variables.

\subsection{Structural model}

The SEM analysis showed that satisfaction directly, positively, and significantly did affect stickiness $(\beta=0.645, \mathrm{t}=17.096$, $\mathrm{p}=0.000)$; whereas trust $\operatorname{did} \operatorname{not}(\beta=0.020, \mathrm{t}=0.551, \mathrm{p}=0.581)$; thus, while H1 was supported, $\mathrm{H} 2$ was not.

Table 6

Summary of proposed results for the theoretical model

\begin{tabular}{lllll}
\hline Research Proposed Paths & Coefficient Value & t-value & p-value & Empirical Evidence \\
\hline $\mathrm{H} 1: \mathrm{SA} \rightarrow$ ST & 0.645 & 17.096 & 0.000 & Supported \\
$\mathrm{H} 2: \mathrm{TR} \rightarrow \mathrm{ST}$ & 0.020 & 0.551 & 0.581 & Not Supported \\
$\mathrm{H} 3: \mathrm{HV} \rightarrow \mathrm{SA}$ & 0.293 & 7.631 & 0.000 & Supported \\
$\mathrm{H} 4: \mathrm{HV} \rightarrow \mathrm{TR}$ & 0.009 & 0.228 & 0.819 & Not Supported \\
$\mathrm{H} 5: \mathrm{SV} \rightarrow \mathrm{SA}$ & 0.109 & 3.376 & 0.000 & Supported \\
$\mathrm{H} 6: \mathrm{SV} \rightarrow$ TR & 0.238 & 7.089 & 0.000 & Supported \\
$\mathrm{H} 7: \mathrm{EV} \rightarrow$ SA & 0.100 & 2.817 & 0.005 & Supported \\
$\mathrm{H} 8: \mathrm{EV} \rightarrow$ TR & 0.186 & 5.025 & 0.000 & Supported \\
\hline
\end{tabular}

SA: Satisfaction; ST: Stickiness; TR: Trust; HV: Hedonic Value; EV: Emotional Value; and SV: Social Value. 
Furthermore, the results showed that while hedonic value affected satisfaction, it did not impact trust; thus, H3 was supported, whereas $\mathrm{H} 4$ was not. However, we found that emotional and social values impacted both satisfaction and trust. Consequently, H5, H6, H7, and H8 were supported. Moreover, the coefficient of determination $\mathrm{R}^{2}$ for the endogenous research variables for Trust, Satisfaction, and Stickiness were $0.129,0.132$, and 0.367 respectively, which indicates that the model does account for the variation of the proposed model.

\section{Discussion}

This study explored the impact of satisfaction and trust on stickiness to Facebook. Also, it proposed that hedonic value, emotional value, and social value act as critical antecedents to Facebook stickiness. As well, social, hedonic and emotional values affect the levels of trust and satisfaction. Satisfaction is critical for the stickiness to SNS; therefore, businesses strive to improve their products and services to satisfy their customers' demands better. Thus, this study suggested that satisfaction has a positive impact on stickiness to SNS. The study analysis showed that H1 was supported. So, satisfaction has a significant positive effect on stickiness. Our finding aligns with the results in the study conducted by (Bataineh et al., 2015) and (Wu et al., 2014) which found that customers' positive past experience with SNS will influence them to stick to the same company's sites. In addition, customers stick to sites that do not cause them any harm. Therefore, customers will have more trust in a site, when the site performs the service, it promised.

The second hypothesis suggested that trust has a positive impact on stickiness to SNS. However, the study analysis did not support H2. Therefore, trust did not produce any impact on stickiness. In previous research trust was found significant for mature and experienced users toward continuance intention to use specific pages on Facebook not the whole platform as well as in the privacy-risk context (Lin et al., 2011; Zong et al., 2019; Warner-Søderholm et al., 2018).

Accordingly, the results show that satisfaction is the most significant factor affecting users' stickiness to SNS when comparing it to trust. A possible explanation for these results may be that users assess the values perceived from a site more than how much they trust it. Thus, users with different degrees of trust indeed have different value models. Furthermore, the study argues that hedonic value has a positive impact on trust and satisfaction through $\mathrm{H} 3$ and H4. Hedonic value can be manifested in enjoyable content such as games. The model test for all respondents indicates that hedonic value (H3) produced a positive impact on satisfaction. This finding aligns with the results in the study conducted by (Sweeney \& Soutar, 2001). Probably, Facebook's active effort in popularizing applications and the widely played embedded games have contributed to this outcome. The study results agree with (Yang \& Lin, 2014), where they indicate that hedonic value can be manifested in enjoyable content such as games and increase users' satisfaction. Meanwhile, hedonic value (H4) did not have a positive impact on trust and this can be explained as enjoyment or entertainment are considered as the most significant antecedents to satisfaction (Basak \& Calisir, 2015). However, the study analysis showed that social value impacted both satisfaction and trust. Thus, the study accepted both hypotheses H5 and H6. The study results of H5 and H6 agree with the previous findings of (Ye et al., 2019; Gan \& Wang, 2017; Yu et al., 2013) where they indicated that social interactions not only enhance customers' trust but also contribute in developing satisfaction towards SNS. As discussed by (Beldad \& Hegner, 2017), the success of an online service depends not only on the perceived benefits it brings but also on the level of trust users have on the service, the technology used for service delivery, and the party behind the service. Although Facebook has been naturally deemed as a social interaction tool, such perception would not exist for low-trust people. Without trust as the basis, social interaction would be fragile and cannot last for the long term, which explains the result for accepting H5 and H6. Furthermore, the study analysis found that emotional value impacted both satisfaction and trust. Hence, the study accepted $\mathrm{H} 7$ and $\mathrm{H} 8$. The study results for H7 and H8 agree with the outcome of (M. R. Lee et al., 2014) and (Sun et al., 2014) where they indicated that people join SNS to gain emotional support from friends and people in their social circle regardless of the effectiveness or the efficiency of the outcomes. It creates a safe environment for sharing a personal feeling with others.

\section{Implications}

\subsection{Theoretical implications}

The current research has enriched the existing study in the fields of customers' satisfaction and trust on stickiness to Facebook. This study has verified the previous theoretical argument of (Hong et al., 2017; Yang et al., 2018) where they adopted the value-based model to explain how SNS users continue to stick to Facebook. Also, the stream of this study focuses on different types of values, such as social value, hedonic value, and emotional value and how they influence users' stickiness to SNS. Furthermore, this study suggested that satisfaction has a positive impact on stickiness to SNS. Also, this research is one of the earliest studies that proved that customer value creation serves as an important driving factor for customer satisfaction to generate stickiness to SNS. Besides, the study findings have enriched the existing studies by exploring deeper into the relationship between customer values and stickiness to SNS which have provided a preliminary explanation for the different degrees of influence by the different types of values. The study analysis indicated that the effects of satisfaction, hedonic value, and emotional value have the greatest impact on stickiness. Satisfaction positively and significantly affected stickiness. Also, the results showed that hedonic, social, and emotional values affected satisfaction. The study added to the existing 
literature that trust did not have a significant effect on stickiness to Facebook as the ultimate goal after SNS continuance intention (Zong et al., 2019). Also, hedonic value did not have a positive effect on trust. The research findings can enrich our understanding regarding the impact of satisfaction and trust on stickiness to Facebook through the roles of hedonic, emotional, and social values.

\subsection{Practical implications}

This study findings can provide guidelines for policymakers and designers of SNS. Therefore, marketers and administrators of SNS need to understand the factors that affect users' stickiness to SNS such as Facebook. Hence, understanding the factors contributing to SNS stickiness is critical for the long-term sustainability of SNS. This study analysis was able to explain the relationship between perceived values, trust, and satisfaction to provide better tools for decision-makers to understand SNS stickiness motivational factors. Hence, users' expectations act as a baseline for evaluating social media platforms. Businesses strive to improve their products and services to better satisfy their customers' demands. Consequently, SNS managers should evaluate users' experience with SNS to develop the right strategy for customers to stick to these sites and keep using their services. For that purpose, SNS providers can improve users' satisfaction by increasing the added values from using their services. This study focuses on hedonic value; accordingly, social media decision-makers need to make shopping more enjoyable and fun to improve the customers shopping experience and to increase satisfaction. Moreover, marketers need to pay full attention to social value by adding more interactive features such as comments, likes, and shares to build social image and increase one's social influence. This study discovered that social value has a positive impact on trust and satisfaction. Users perceive SNS as sources of empathy and caring feelings, and they experience satisfaction when such emotional needs are fulfilled through SNS. Accordingly, this research suggests that emotional value has a positive impact on trust and satisfaction. Therefore, understanding users' different reactions to technology affordances, SNSs administrators can take efficient measures and develop new applications to increase the switching cost and retain users for a longer time.

\section{Research limitations and future research}

This study was conducted on undergraduate students at one university in Jordan, which would limit the generalizability to other contexts. Also, testing this model in new settings and countries can provide valuable insights regarding the antecedents and outcomes of Facebook stickiness in different national and international cultures. Thus, future research can test this study by collecting data from other age categories, universities, as well as from other contexts to develop more generalizable results and increase the credibility of the results. Another limitation is related to the nature of the data collection as a questionnaire method was used that may have created a common method variance/bias. Thus, future research could employ different data collection methods (i.e. qualitative) to improve the reduction of common method variance/bias. To ensure users stickiness and continuing using a specific social networking platform, users should realize that they are spending their time on valuable and useful contents. Thus, examining the proposed model based on data collected from different social network sites users would be very useful for managers to maintain enhancing the provided services and values to the users. Consequently, the research findings are very critical for SNS management as they can guarantee that users are sticking to the specific platform without switching to another platform. Finally, the findings of this research are highly significant to the literature on this research area, and it is hoped to be followed by further crucial research to shed more light on their importance.

\section{References}

Alex, H. (2019). Facebook usage falling after privacy scandals, data suggests. The Guardian. https://www.theguardian.com/technology/2019/jun/20/facebook-usage-collapsed-since-scandal-data-shows

Amoroso, D. L., \& Chen, Y. (2017). Constructs Affecting Continuance Intention in Consumers With Mobile Financial Apps: a Dual Factor Approach. Journal of Information Technology Management, XXVIII(3), 24. http://files/2556/Amoroso and Chen - 2017 - CONSTRUCTS AFFECTING CONTINUANCE INTENTION IN CONS.pdf

Authors, F. (2016). Journal of Research in Interactive Marketing.

Bagozzi, R., \& Yi, Y. (1988). On the evaluation of structural equation models. Journal of the Academy of Marketing Sciences , 16(1), 74-94.

Basak, E., \& Calisir, F. (2015). An empirical study on factors affecting continuance intention of using Facebook. In Computers in Human Behavior (Vol. 48, Issue April 2016, pp. 181-189). https://doi.org/10.1016/j.chb.2015.01.055

Bataineh, A. Q., Al-Abdallah, G. M., \& Alkharabsheh, A. M. (2015). Determinants of continuance intention to use social networking sites SNS's: studying the case of Facebook. International Journal of Marketing Studies, 7(4), $121-135$. https://doi.org/10.5539/ijms.v7n4p121

Beldad, A. D., \& Hegner, S. M. (2017). More Photos From Me to Thee: Factors Influencing the Intention to Continue Sharing Personal Photos on an Online Social Networking (OSN) Site among Young Adults in the Netherlands. International Journal of Human-Computer Interaction, 33(5), 410-422. https://doi.org/10.1080/10447318.2016.1254890

Chang, S. E., Liu, A. Y., \& Shen, W. C. (2017). User trust in social networking services: A comparison of Facebook and LinkedIn. Computers in Human Behavior, 69, 207-217. https://doi.org/10.1016/j.chb.2016.12.013

Cocosila, M., \& Igonor, A. (2014). How important is the " social " in social networking? A perceived value empirical investigation. https://doi.org/10.1108/ITP-03-2014-0055 
Cocosila, M., \& Igonor, A. (2015). How important is the "social" in social networking? A perceived value empirical investigation. Information Technology and People, 28(2), 366-382. https://doi.org/10.1108/ITP-03-2014-0055

Creswell, J. W. (2009). Creswell, J. (2009), Research Design: Qualitative, Quantitative, and Mixed Methods Approaches, 3rd edition, . (3rd (ed.)). Thousand Oaks, Sage Publications.

DeLone, W. H., \& McLean, E. R. (2003). The DeLone and McLean model of information systems success: A ten-year update. Journal of Management Information Systems, 19(4), 9-30. https://doi.org/10.1080/07421222.2003.11045748

Duffy, K. (n.d.). WhatsApp says you shouldn't worry about it sharing personal data with Facebook. Experts say you should switch to "highly trusted" Signal. Businessinsider.

Gan, C., \& Wang, W. (2017). The influence of perceived value on purchase intention in social commerce context. Internet Research, 27(4), 772-785. http://10.0.4.84/IntR-06-20160164\%0Ahttp://search.ebscohost.com/login.aspx?direct=true\&db=1lf\&AN=124365799\&site=ehost-live

Gong, X., Liu, Z., Zheng, X., \& Wu, T. (2018). Why are experienced users of WeChat likely to continue using the app? Asia Pacific Journal of Marketing and Logistics, 30(4), 1013-1039. https://doi.org/10.1108/APJML-10-2017-0246

Grabner-Kräuter, S., \& Bitter, S. (2014). Trust in online social networks: A multifaceted perspective. Forum for Social Economics, 44(1), 48-68. https://doi.org/10.1080/07360932.2013.781517

Ha, H. Y., \& Pan, H. (2018). The evolution of perceived security: the temporal role of SNS information perceptions. Internet Research, 28(4), 1055-1078. https://doi.org/10.1108/IntR-02-2017-0047

Hair, J. (2007). Research Methods for Business . New York, NY: Wiley 2007. , ISBN: 047003404 0. In Education + Training (4th ed., Vol. 49, Issue 4). https://doi.org/10.1108/et.2007.49.4.336.2

Hair, J., Black, W., Babin, B., \& Anderson, R. (2014). Multivariate Data Analysis. In Pearson custom library. https://doi.org/10.1038/259433b0

Herzallah, F., \& Mukhtar, M. (2016). The impact of percieved usefulness, ease of use and trust on managers' acceptance of e-commerce services in small and medium-sized enterprises (SMEs) in Palestine. International Journal on Advanced Science, Engineering and Information Technology, 6(6), 922-929. https://doi.org/10.18517/ijaseit.6.6.1377

Holbrook, M. B., Wharton, P. G., Carnegie, A. K., Northwestern, L., Stanford, B. M., Ramond, C., Chicago, G. S., \& Rutgers, B. W. (2006). Consumption experience, customer value, and subjective personal introspection: An illustrative photographic essay. 59, 714-725. https://doi.org/10.1016/j.jbusres.2006.01.008

Hong, J. C., Lin, P. H., \& Hsieh, P. C. (2017). The effect of consumer innovativeness on perceived value and continuance intention to use smartwatch. Computers in Human Behavior, 67, 264-272. https://doi.org/10.1016/j.chb.2016.11.001

Hsiao, C., Chang, L. J., \& Tang, K. (2015). Exploring the influential factors in continuance usage of mobile social Apps: Satisfaction, habit, and customer value perspectives. TELEMATICS AND INFORMATICS. https://doi.org/10.1016/j.tele.2015.08.014

Hsu, C. L., \& Lin, J. C. C. (2015). What drives purchase intention for paid mobile apps?-An expectation confirmation model with perceived value. Electronic Commerce Research and Applications, 14(1), 46-57. https://doi.org/10.1016/j.elerap.2014.11.003

Hsu, C., \& Lin, J. C. (2016). Technological Forecasting \& Social Change Effect of perceived value and social in fl uences on mobile app stickiness and in-app purchase intention. Technological Forecasting \& Social Change. https://doi.org/10.1016/j.techfore.2016.04.012

Hsu, C., \& Lin, J. C. (2020). Examining Social Networking O2O Apps User Loyalty Examining Social Networking O2O Apps User Loyalty. https://doi.org/10.1080/08874417.2018.1535261

Ibrahim, A. N. H., \& Borhan, M. N. (2020). The Interrelationship Between Perceived Quality, Perceived Value and User Satisfaction Towards Behavioral Intention in Public Transportation: A Review of the Evidence. International Journal on Advanced Science, Engineering and Information Technology, 10(5), 2048. https://doi.org/10.18517/ijaseit.10.5.12818

Jia, H., \& Xu, H. (2015). Measuring individuals' concerns over collective privacy on social networking sites. 2015 International Conference on Information Systems: Exploring the Information Frontier, ICIS 2015.

Kim, D. J., Ferrin, D. L., \& Rao, H. R. (2008). A trust-based consumer decision-making model in electronic commerce: The role of trust, perceived risk, and their antecedents. Decision Support Systems, 44(2), 544-564. https://doi.org/10.1016/j.dss.2007.07.001

Krejcie, R. V, \& Morgan, D. W. (1970). Determining sample size for research activities. Education and Psychological Measurement, 30, 607-610. https://doi.org/10.1177/001316447003000308

Lankton, N. K., \& McKnight, D. H. (2011). What does it mean to trust facebook? Examining technology and interpersonal trust beliefs. Data Base for Advances in Information Systems, 42(2), 32-54. https://doi.org/10.1145/1989098.1989101

Larcker, D. F., Fornell, C., \& Larcker, D. F. (1981). Evaluating structural equation models with unobservable variables and measurement error. Journal of Marketing Research, 18(1), 456-464. https://doi.org/10.2307/3151312

Lee, M. R., Yen, D. C., \& Hsiao, C. Y. (2014). Understanding the perceived community value of Facebook users. Computers in Human Behavior, 35, 350-358. https://doi.org/10.1016/j.chb.2014.03.018

Lee, S., Kim, B. G., \& Lee, S. (2017). The impact of qualities of social network service on the continuance usage intention. Management Decision, 55(4), 701-729. https://doi.org/10.1108/MD-10-2016-0731

Lin, H., Fan, W., \& Chau, P. Y. K. (2014). Determinants of users' continuance of social networking sites: A self-regulation perspective. Information and Management, 51(5), 595-603. https://doi.org/10.1016/j.im.2014.03.010

Lin, K., Lu, H., \& Ph, D. (2011). Intention to Continue Using Facebook Fan Pages from the Perspective of Social Capital Theory. 14(10). https://doi.org/10.1089/cyber.2010.0472 
Lita, R. P., \& Meuthia. (2018). An empirical study of sme's embroidery website in Indonesia: A proposed model of website re-visit intention. International Journal on Advanced Science, Engineering and Information Technology, 8(4), 1234-1245. https://doi.org/10.18517/ijaseit.8.4.2647

Newkirk, H. E., \& Lederer, A. L. (2006). The effectiveness of strategic information systems planning under environmental uncertainty. Information and Management, 43(4), 481-501. https://doi.org/10.1016/j.im.2005.12.001

Noordin, S., Ashaari, N. S., \& Wook, T. S. M. T. (2018). A proposed model for Virtual Fitting Room based on usability and profound emotional elements. International Journal on Advanced Science, Engineering and Information Technology, 8(6), 2332-2340. https://doi.org/10.18517/ijaseit.8.6.6440

O'Rourke, N., \& Hatcher, L. (2013). A step-by-step approach to using SAS for factor analysis and structural equation modeling. In The Companion to Language Assessment. https://doi.org/10.1002/9781118411360.wbcla114

Odel, C. O. M. (2001). U NDERSTANDING I NFORMATION S YSTEMS C ONTINUANCE : A N E XPECTATION -. 25(3), 351-370.

Rex B. Kline. (2011). Principles and Practice of Structural Equation Modeling. In The Guilford Press (2nd ed.). The Guilford Press.

Shao, Z., Zhang, L., \& Chen, K. (2020). Examining user satisfaction and stickiness in social networking sites from a technology affordance lens: uncovering the moderating effect of user experience. 120(7), 1331-1360. https://doi.org/10.1108/IMDS-11-2019-0614

Sun, Y., Liu, L., Peng, X., Dong, Y., \& Barnes, S. J. (2014). Understanding Chinese users' continuance intention toward online social networks: An integrative theoretical model. Electronic Markets, $24(1)$, 57-66. https://doi.org/10.1007/s12525-013-0131-9

Sweeney, J. C., \& Soutar, G. N. (2001). Consumer perceived value: The development of a multiple item scale. Journal of Retailing, 77(2), 203-220. https://doi.org/10.1016/S0022-4359(01)00041-0

Thomas, M. (2020). Do All Roads Lead to Rome? Exploring the Relationship Between Social Referrals , Referral Propensity and Stickiness to Video-on-Demand Websites. https://doi.org/10.1007/s12599-020-00660-1

Tsai, J. C. A., \& Hung, S. Y. (2019). Examination of community identification and interpersonal trust on continuous use intention: Evidence from experienced online community members. Information and Management, 56(4), $552-569$. https://doi.org/10.1016/j.im.2018.09.014

Wang, C., Teo, T. S. H. H., \& Liu, L. (2020). Perceived value and continuance intention in mobile government service in China. Telematics and Informatics, 48(January), 101348. https://doi.org/10.1016/j.tele.2020.101348

Warner-Søderholm, G., Bertsch, A., Sawe, E., Lee, D., Wolfe, T., Meyer, J., Engel, J., \& Fatilua, U. N. (2018). Who trusts social media? Computers in Human Behavior, 81, 303-315. https://doi.org/10.1016/j.chb.2017.12.026

Weisbaum, H. (2019). Trust in Facebook has dropped by 66 percent since the Cambridge Analytica scandal. NBC News, April 18. https://www.nbcnews.com/business/consumer/trust-facebook-has-dropped-51-percent-cambridge-analytica-scandaln867011

Wongkitrungrueng, A., \& Assarut, N. (2020). The role of live streaming in building consumer trust and engagement with social commerce sellers. Journal of Business Research, 117, 543-556. https://doi.org/10.1016/j.jbusres.2018.08.032

Wu, C. C., Huang, Y., \& Hsu, C. L. (2014). Benevolence trust: A key determinant of user continuance use of online social networks. Information Systems and E-Business Management, 12(2), 189-211. https://doi.org/10.1007/s10257-013-02161

Yang, H.-L., \& Lin, C.-L. (2014). Why do people stick to Facebook web site? A value theory-based view. Information Technology and People, 27(1), 21-37. https://doi.org/10.1108/ITP-11-2012-0130

Yang, S., Jiang, H., Yao, J., Chen, Y., \& Wei, J. (2018). Perceived values on mobile GMS continuance: A perspective from perceived integration and interactivity. Computers in Human Behavior, 89(June), $16-26$. https://doi.org/10.1016/j.chb.2018.07.032

Ye, S., Ying, T., Zhou, L., \& Wang, T. (2019). Enhancing customer trust in peer-to-peer accommodation: A "soft" strategy via social presence. International Journal of Hospitality Management, 79, 1-10. https://doi.org/10.1016/j.ijhm.2018.11.017

Yoo, J., Choi, S., Choi, M., \& Rho, J. (2014). Why people use Twitter: Social conformity and social value perspectives. Online Information Review, 38(2), 265-283. https://doi.org/10.1108/OIR-11-2012-0210

Yu, J., Zo, H., Choi, M. K., \& Ciganek, A. P. (2013). User acceptance of location-based social networking services: An extended perspective of perceived value. Online Information Review, 37(5), 711-730. https://doi.org/10.1108/OIR-122011-0202

Zhang, C. B., Li, Y. N., Wu, B., \& Li, D. J. (2017). How WeChat can retain users: Roles of network externalities, social interaction ties, and perceived values in building continuance intention. Computers in Human Behavior, 69, $284-293$. https://doi.org/10.1016/j.chb.2016.11.069

Zhang, Xin, Ding, X., \& Ma, L. (2020). The influences of information overload and social overload on intention to switch in social media. Behaviour and Information Technology. https://doi.org/10.1080/0144929X.2020.1800820

Zhang, Xing, Liu, S., Chen, X., Wang, L., Gao, B., \& Zhu, Q. (2018). Health information privacy concerns, antecedents, and information disclosure intention in online health communities. Information and Management, 55(4), $482-493$. https://doi.org/10.1016/j.im.2017.11.003

Zong, W., Yang, J., \& Bao, Z. (2019). Social network fatigue affecting continuance intention of social networking services: The case of WeChat users in China's universities. Data Technologies and Applications, 53(1), $123-139$. 


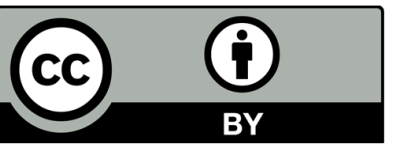

(C) 2021 by the authors; licensee Growing Science, Canada. This is an open access article distributed under the terms and conditions of the Creative Commons Attribution (CC-BY) license (http://creativecommons.org/licenses/by/4.0/). 